\title{
Correction to: Decision-making for structural parameters of injection mold gating system based on agent model and intelligent algorithm
}

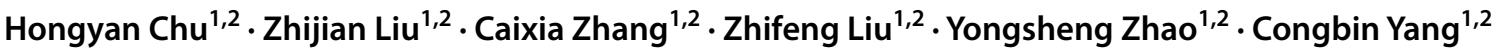 \\ Published online: 6 February 2022 \\ (c) The Author(s), under exclusive licence to Springer-Verlag London Ltd., part of Springer Nature 2022
}

\section{Correction to: The International Journal of Advanced Manufacturing Technology https://doi.org/10.1007/s00170-022-08756-6}

The original article contained a mistake.

The corresponding author of this paper should be Caixia Zhang.

The original article has been corrected.

Publisher's Note Springer Nature remains neutral with regard to jurisdictional claims in published maps and institutional affiliations.

The original article can be found online at https://doi.org/10.1007/ s00170-022-08756-6.

Caixia Zhang

Zhang-cx15@bjut.edu.cn

1 Institute of Advanced Manufacturing and Intelligent

Technology, Beijing University of Technology,

Beijing 100124, China

2 Beijing Key Laboratory of Advanced Manufacturing

Technology, Beijing University of Technology,

Beijing 100124, China 